\title{
MULTI-OBJECTIVE GOAL PROGRAMMING AND ITS APPLICATIONS: A REVIEW
}

\begin{tabular}{|l|l|}
\hline Jyoti & Himani Mannan \\
HAS Department & HAS Department \\
YMCA University of Science Technology & YMCA University of Science and Technology \\
Faridabad, India & Faridabad, India \\
jgrover1981@gmail.com & himanimannan07@ gmail.com \\
\hline
\end{tabular}

\begin{abstract}
Today, analysts face optimization problems with a set of objectives, often inconsistent with each other. Multiobjective Goal Programming algorithm plays an important role in dealing with these real world problems involving nondeterministic systems for which multiple and conflicting objectives exist. In this paper we will study Multi-Objective Goal Programming algorithm, its history, current methods for solving multi-objective problems and its various applications.
\end{abstract}

Keywords-Multi-objective programming;Lexicographic Goal Programming; Weighted Goal Programming; Preemptive Goal Programming

\section{INTRODUCTION}

Decision making is often characterized by an attempt to satisfy a set of potentially conflicting objectives in an environment composed of limited resources, divergent interests and an annoying priorities in order to deal with situations in which all objectives cannot be completely and/or simultaneously satisfied. Goal Programming (GP) is a type of optimization that handles such multi-criteria decision-making problems; thus called Multi-objective Goal Programming (MOGP). There is no single optimal solution for these problems; rather an interaction among different objectives give rise to a set of compromised solutions.

The GP was first introduced by Charnes and Cooper (1961). This solution approach was then applieded and extended by Ijiri (1965), Charnes et al. (1963, 1968), Lee (1972), Ignizio (1976) and later by Romero (1992). GP has a large number of research papers introducing it and studying its applications covering a huge amount of areas and disciplines.

Hwang et al. (1980) and Evans (1984), depending on the decision-maker's preferences categorized [2] the variants of GP into four categories:

- No articulation of the decision-maker's preferences : In this method preferences of decision maker are not considered.

- Priori Method: In this method preferences of decision maker are specified before solving the problem.

- Interactive Method: In this method preferences of decision maker are considered during the solution, in response to their opinions with which the solution is generated till that point.

- Posteriori Method: In this method first the solution is generated and then decision maker's preferences are taken in consideration with respect to the solution.

MOGP is one of the Posteriori Methods most commonly used for various multi-dimensional optimization problems.

\section{MOGP MODEL FORMULATION}

The formulation of GP model is similar to that of LP model. The general model can be stated as follows: Objective function:

$\mathrm{m}$

$$
\text { Minimize: } \mathrm{z}=\sum_{\mathrm{I}} \mathrm{w}_{\mathrm{i}}\left(\mathrm{d}_{\mathrm{i}}^{-}+\mathrm{d}_{\mathrm{i}}^{+}\right) \quad ; \mathrm{I}=1,2, \ldots,
$$

Subject To:

$\mathrm{m}$,

$\mathrm{n}$

where,

$\mathrm{b}_{\mathrm{i}}=\mathrm{m}$-component column expressing $\mathrm{m}$ goals

$$
\begin{gathered}
\mathrm{a}_{\mathrm{ij}}=\text { coefficient for the } \mathrm{j}^{\text {th }} \text { decision variable in the } \mathrm{i}^{\text {th }} \\
\text { constraint }
\end{gathered}
$$

$\mathrm{x}_{\mathrm{j}}=$ decision variable

$\mathrm{w}_{\mathrm{i}}=$ weights of each goal

$\mathrm{d}_{\mathrm{i}}^{-}=$deviational variable representing the amount of underachievement of $i^{\text {th }}$ goal

$\mathrm{d}_{\mathrm{i}}^{+}=$deviational variable representing the amount of overachievement of $i^{\text {th }}$ goal

In case, goals are classified in $\mathrm{k}$ ranks, the pre-emptive priority

factors $\left(\mathrm{P}_{1}, \mathrm{P}_{2}, \ldots\right.$. And so on) should be assigned to deviational variables $\mathrm{d}_{\mathrm{i}}{ }^{-}$and $\mathrm{d}_{\mathrm{i}}{ }^{+}$according to their order of importance.

\section{TYPES OF MOGP MODELS :}

The basic concept of MOGP is whether goals are attainable or no, an objective may be stated in which optimization gives result as close as possible to the desired goal. Thus, based on definition of objective function MOGP is classified as follows: 


\section{A. Multi-goal with equal (no) priorities:}

The multi-goal equal priority model is easy to deal with mathematically but is the least practical of all the

formulations. Its general model can be stated as follows: Objective function:

$$
\begin{aligned}
& \min \quad \mathrm{z}=\sum_{\mathrm{I}} \quad \mathrm{d}_{\mathrm{i}}^{-}+\mathrm{d}_{\mathrm{i}}^{+} \quad ; \mathrm{I}=1,2, \ldots, \mathrm{m} \\
& \text { Subject To: } \quad \sum_{\mathrm{j}} \mathrm{a}_{\mathrm{ij}}+\mathrm{d}_{\mathrm{i}}^{-}-\mathrm{d}_{\mathrm{i}}^{+}=\mathrm{b}_{\mathrm{i}} \quad ; \mathrm{I}=1,2, \ldots \text {, } \\
& \mathrm{j}=1,2, \ldots \\
& \text { and } \mathrm{x}_{\mathrm{j}}, \mathrm{d}_{\mathrm{i}}^{-}, \mathrm{d}_{\mathrm{i}}^{+} \geq 0 \quad ; \text { for all } \mathrm{I}, \mathrm{j}
\end{aligned}
$$
$\mathrm{m}$,$$
\mathrm{n}
$$

Here no weights and priorities are assigned in the objective function.

Some actual cases may exist where all goals have equal priorities, but the output from an equal-priority model should be examined properly for compatibility.

\section{B. Lexicographic (Pre-emptive) Goal Programming}

\section{$(L G P)$ :}

Lexicographic GP simultaneously satisfy various preferentially ordered goals according to the decision making situation through the use of priority coefficients $\left(\mathrm{p}_{\mathrm{i}}\right.$ 's). All goals (deviational variables) that have a top or first priority are assigned an objective function value of $\mathrm{p}_{1}$, the goals considered to be second in priority are assigned value $\mathrm{p}_{2}$ and the process goes on until all goals are ranked.

The general algebraic representation of LGP is given as:

Objective function:

$$
\text { lexi } \min \mathrm{z}=\sum_{\mathrm{I}} \mathrm{p}_{\mathrm{i}}\left(\mathrm{d}_{\mathrm{i}}{ }^{-}+\mathrm{d}_{\mathrm{i}}{ }^{+}\right) \quad ; \mathrm{I}=1,2, \ldots,
$$

$\mathrm{m}$

Subject To:

$\sum_{\mathrm{j}} \mathrm{a}_{\mathrm{ij}}+\mathrm{d}_{\mathrm{i}}^{-}-\mathrm{d}_{\mathrm{i}}^{+}=\mathrm{b}_{\mathrm{i}}$

$; \mathrm{I}=1,2, \ldots$,

$\mathrm{m}$,

$$
\mathrm{j}=1,2, \ldots,
$$

$\mathrm{n}$

$$
\text { and } \mathrm{X}_{\mathrm{j}}, \mathrm{d}_{\mathrm{i}}^{-}, \mathrm{d}_{\mathrm{i}}^{+} \geq 0 \quad ; \text { for all } \mathrm{I}, \mathrm{j}
$$

The coefficients $\mathrm{p}_{1}, \mathrm{p}_{2}, \ldots$, are not variables or parameters. They do not assume a numerical value, they simply represent levels for priorities.

The LGP was introduced by Ijiri (1965) and developed by Lee (1972) [19] and Ignizio (1976).Later utilizing Orumie and Ebong (2011) initial table with modification, Orumie and Ebong (2013) discovered a new algorithm for LGP. The procedure considered goal constraints as both the objective function and constraints. The objective function becomes the prioritized deviational variables and solves sequentially starting from the highest priority level to the lowest [3].

\section{Weighted Goal Programming (WGP) :}

In WGP, a differential weight is assigned to each of the objectives (deviational variables), used to reflect difference of importance within the same priority level.
The general algebraic representation of WGP as presented in Ken and Perushek [1],also mentioned in [4] Orumie and Ebong (2014), is given as:

Objective function:

$$
\begin{aligned}
& \min \mathrm{z}=\sum_{\mathrm{I}}\left(\mathrm{w}_{\mathrm{i}}{ }^{-} \mathrm{d}_{\mathrm{i}}^{-}+\mathrm{w}_{\mathrm{i}}^{+} \mathrm{d}_{\mathrm{i}}^{+}\right) \quad ; \mathrm{I}=1,2, \ldots, \\
& \text { m } \\
& \text { Subject To: } \quad \sum_{\mathrm{j}} \mathrm{a}_{\mathrm{ij}}+\mathrm{d}_{\mathrm{i}}^{-}-\mathrm{d}_{\mathrm{i}}^{+}=\mathrm{b}_{\mathrm{i}} \quad ; \mathrm{I}=1,2, \ldots, \\
& \mathrm{m} \text {, } \\
& \mathrm{j}=1,2, \ldots,
\end{aligned}
$$$$
\text { n }
$$$$
\text { and } \mathrm{x}_{\mathrm{j}}, \mathrm{d}_{\mathrm{i}}^{-}, \mathrm{d}_{\mathrm{i}}^{+} \geq 0 \quad ; \text { for all } \mathrm{I}, \mathrm{j}
$$

Where $\mathrm{w}_{\mathrm{i}}^{-}$and $\mathrm{w}_{\mathrm{i}}^{+}$are numerical weights associated with negative and positive deviational variables $\mathrm{d}_{i}^{-}$and $\mathrm{d}_{i}^{+}$ respectively which denotes how far the decision is from the goal and how much the decision has exceeded the goal respectively.

\section{Prioritized (Weighted Preemptive) Goal Programming:}

In this GP problem, both weights and priorities are assigned to the deviational variables in the objective function.

\section{Orumie and}

Ebong [4] explained that, this occurs when the goals can be categorized into groups where the goals within each group are of equal importance, but there are slight differences between the groups in their level of importance. Here, Weighted GP can be used within each group in-turn while Preemptive GP deals with each group in order of importance.

Various other models have been introduced like:

- Fuzzy Goal Programming:

Apart from GP techniques discussed above, Fuzzy Logic is another technique for multi-objective optimization. The theory of Fuzzy sets is based on a multivalued logic where in a statement can be partly true and partly false at the same time. In fuzzy logic, the degree of truthfulness of a statement is expressed by a membership function, $\mathrm{m}$, in the range $[0,1]$. A value of $\mathrm{m}=0$ indicates that the statement is false, while $m=1$ indicates that the statement is true. The fuzzy logic approach differs from binary logic, in that binary logic allows a statement to be either false or true.

In recent years the use of fuzzy logic for multi -objective optimization has gained momentum, with applications in various areas like forest planning [5] and resource allocation Liang.T-F (2009) [13] focuses on developing a two-phase fuzzy mathematical programming approach for solving the multi-objective project management decision problem in a fuzzy environment.

\section{- Zero-One Goal Programming.}

Zero-one GP is one of the GP techniques which is now a daysbeing used in various optimization process. Ertugrul et al. (2002) presented a combined analytic network process (ANP) and a zero-one goal programming (ZOGP) approach in product planning in Quality Function Deployment (QFD) to incorporate customer's needs and the Product Technical 


\section{- \\ ELK \\ Asia Pacific Journals}

Requirements (PTRs) systematically into the product design phase. Considering resource limitations and multiobjective nature of the problem (important levels of product technical requirement using ANP, cost budget, extendibility level and manufacturability level goals.

\section{- Integer Goal Programming:}

Integer GP is another area with growing popularity. In fact, many applications of GP require the use of discrete variables. Lee and Morris(1997) [25] , Markland and Vickery(1986) [26] worked on Integer GP methods and its computer application.

\section{APPLICATIONS OF MOGP AND LITERATURE REVIEWED}

A lot of research has been carried out in the applications of goal programming in different fields. Alade et al. (1998) developed a multi-objective model for the planning of developing countries. In their model, they examined industrial structure, capital efficiency, labour force, import inputs for export, investment planning etc. and it was applied for Indian economy.

Heady (1954) studied MOGP models for proper allocation of cultivable land to cropping plan. In the mid -1960 s to 1980s, the different linear programming (LP) approaches to agricultural planning problem were introduced by Glen (1987). LP model have been successfully used to the farm planning problems. The MOGP (Ignizio 1976) [20] as a robust tool for multi - objective decision analysis has been successfully implemented to different farm planning problems. Adeiobi et al. (2003) [7] applied a linear GP technique to model the farm-family crop production enterprise in the Savannah zone of Nigeria to develop an optimal crop combination that helped the small holder farmers in meeting their most important goals of providing food for the family throughout the year. Latinopoulos et al. (2005) created a MOGP model in which Weighted and Lexicographic GP techniques were employed and implemented that simultaneously maximized farmer's welfare and minimized consequent environmental burden in allocation of land and water resources in irrigated agriculture. Thus, MOGP technique can be used to solve various problems where there is a need to determine an optimum-cropping pattern by considering several goals in agricultural planning and management. Wheeler and Russell (1977) used a GP model to analyze the plantation of the farm in the United Kingdom (also referred in [18]).

Anderle et al. (1994) [5] applied multiple objective goal programming techniques in management of the Mark Twain National Forest in Missouri, by applying fuzzy multiple objective programming technique for resource allocation problems in the forest planning. Goal programming, a MOLP procedure, was introduced as an alternative to linear programming for public forest management planning models incorporating multi-objective planning in the paper of Field et al. (1980) [8]. The Goal Programming (GP) technique in solving agro-forestry management problems involving multiple-objectives has
ELK Asia Pacific Journals - Special Issue ISBN: 978-81-930411-4-7

become a widely used approach in Operation Research studies (Romero, 1986). Diaze-Balteiro and Romero (2003) developed a GP model that incorporates carbon sequestration, in terms of total carbon balance, as a complimentary objective with other criteria including maximizing net present value, quality of harvest volume , area control in forest management.

Kenneth et al. (1995) [9] presented a prioritized MOGP model that allowed for multiple, conflicting goals in natural resource allocation management's decision problems. Romero and Rehman (1987) reviewed the application of MOGP in fisheries, agricultural land uses , forestry and water management. Cobb and Warner (1973) and Trivedi (1981) used mixed integer MOGP method for resource allocation in order to solve management related problems for quality service.

For solving problem of making project decisions involving a large number of interrelated activities- the planning and scheduling project management, Premchandra(1993) [10] developed a MOGP model. Nhantumbo et al. (2006) presented a Weighted Goal Programming (WGP) approach for planning management and use of woodlands as well as a framework for policy analysis. The methodology was employed to reconcile demands of households, private sector and government of Miombo woodland of South Africa. For scheduling a tour of a marketing executive which is concerned with the determination of appropriate workforce requirement, workforce allocation, Mithirajan and Ramanathan (2006) applied and addressed a goal programming model. Mukherjee K. and Bera A. (1995) [12] examined the project selection decision using goal programming technique. The MOGP model was applied to Indian coal mining industry. The model identified five goal: -Capital investment goal.

-Cost of production goal.

-Profit goal.

-Manpower goal.

-Demand goal.

Gyu and John (2000) [11] applied a goal programming model for project selection and resource planning, using zero-one goal programming (ZOGP) model, which is validated by applying it to case study from the Woodward Governor Company. For solving the multi-objective project management decision problem in a fuzzy environment, a two-phase fuzzy mathematical programming approach was developed by Liang.T-F (2009) [13].

Ertugrul et al. (2002) presented a combined analytic network process (ANP) and a ZOGP approach in product planning in Quality Function Deployment (QFD) to incorporate customer's needs and the Product Technical Requirements (PTRs) systematically into the product design phase. Considering resource limitations and multiobjective nature of the problem (important levels of product technical requirement using ANP, cost budget, extendibility level and manufacturability level goals. Suresh Chand Sharma et al. (2010) [15] proposed a goal programming model for tracking and tackling environmental risk 


\section{- \\ ELK \\ Asia Pacific Journals}

production planning problem that includes minimization of damages and wastes in the milk production system.

Olson compared four goal programming methods; Schniederjans and Kwaks, Lee , Authur and Ravindran And also developed a revised simplex lgorithm (RSM) for solving LGP problem that adopts Schniederjans and Kwaks dual simplex rules applied for the calculation of new tableau elements.

Another interesting development is the utilization of GP as a statistical tool for estimation. Recent studies by Lee and Morris (1977) [25] , Ignizio and Cavalier (1994) and Tamiz et al. (1999), suggested that MOGP could be an alternative to the conventional statistical methods. In fact, MOGP provides more flexibility for modeling the estimation process.

\section{CONCLUSION}

In this paper we have studied various MOGP models ant its applications in many fields. We observe that MOGP have many advantages and disadvantages.

One of the major advantage of MOGP is that due to inclusion of the deviational variables there always exists a solution to the problem provided that the target values are known, and the goals are in feasible region. However, if the targets are wrong then the feasible region is difficult to approach, in which case MOGP could be very inefficient. Despite of MOGP's popularity it has many disadvantages, especially In the case of the aggregation's procedure of deviations related to the objectives having incommensurable units of measurement. Martel and Aouni (1990) introduced the concept of satisfaction functions in order to remedy the incommensurability of the units. Also numerous applications of MOGP are not supported by software and tools to assist decision making process.

Since the efficiency of MOGP solutions completely depends upon the problem and the decision maker and it is almost impossible for the decision maker to achieve ideal goals without the expense of other goal in optimization of multiple goals. Thus a MOGP solution can't be efficient if the targets or weights and priorities assigned to the decision variables by the user are unreasonable. (also given by Zeleny (1981) and Hannan(1985)).

\section{References}

[1] Ken, W.,and Perushek, D.E. (1996). Linear Goal Programming for Academic Library Acquisitions Allocations. http://trace.tennessee.edu/utk_libfpubs/26

[2] Aouni, B. , Kettani, O. (2001). Goal Programming model: A glorious history and a promising future; European Journal of Operational Research 133, 225231.

[3] U.C.Orumie,U.C., Ebong, D.W. (2013). An Efficient Method of Solving Lexicographic Linear Goal Programming Problem; International Journal of Scientificand Research Publications, Volume 3, Issue 10, October 2013. ISSN 2250-3153.

[4] U.C.Orumie,U.C., Ebong, D.W. (2014). A Glorious Literature on Linear Goal Programming Algorithms. American Journal of Operationas Research, 2014, 4, $59-71$.

\section{ELK Asia Pacific Journals - Special Issue} ISBN: 978-81-930411-4-7

[5] Anderle, C., Fedrizzi, M., and Giove, S., Fuzzy multiple objective programming techniques in modeling forest plannig (1994). Department of Computer Science, Eotvos Lorand University.

[6] M. Young, The Technical Writer's Handbook. Mill Valley, CA: University Science, 1989.

[7] A.O. Adeiobi , P.M.Kormawa , W.M.Manyong and J.K.Olayerni. optimal crop combinations under limited resourse conditions : Application of linear GP model to small holder farmers in the driver Savannah zone of Nigeria (2003). Department of Agricultural Economics , University of Ibadan, Nigeria.

[8] R.C.Field , P.E. Dress and J.C. Fortson Complimentary Linear and Goal , Programming Procedures for Timber Harvest Scheduling. Forest Science (1980), 26:pp. 121-133.

[9] E.B.Kenneth and E.T.Bartlett. Resource allocation through Goal Programming , Journal of range management (1995), 28(6).

[10] B.C.Premchandra. Qunatity discount decision under conditions of multiple items, multiple suppliers and resource limitations. International Journal of Production research (1993),29(10):pp.1953-1961 .

[11] C.K.Gyu and E.John (2000), An application of zeroone Goal programming in project selection and resource planning- A case study from the Woodward Governor Company. Computers and operation research, 27:1389-1408.

[12] K.Mukherjee and A . Bera(1995). An application of goal programming in project selection decision- a case study from the Indian coal mining industry . European Journal of operational research,82;15 -25.

[13] T.F.Liang (2009). Fuzzy multi-objective project management decisions using two phase fuzzy goal programming approach. Computers and industrial engineering ,57;1407-1416.

[14] N.Hantumbo and G.Kowero. A Goal Programming model for planning management of Miombo Woodlands (2006), 1:pp.257-283.

[15] S.C.Sharma , D.S.Hada, S.K.Bansal and S.Bafna . A Goal Programming model for solving Environmental risk production planning problem in dairy production system. International Journal of computer science and emerging techniques(2010), 1(4).

[16] J.Kornbluth . A Survey of Gaol Programming . Omega (1973), 1;pp.193-205.

[17] A.Charnes and W.W.Cooper .Goal Programming and multiple objectives optimizations . European General of Operational Research (1977),1:pp.39-54.

[18] N.Sen and M.Nandi . Goal Programming, its applications in management sector- special attension into plantation management: A Rieview.

[19] S.M.Lee (1972) . Goal Programming for decion analysis. Auerbach, Philadelphia.

[20] J.P.Ignizio(1976) . Goal Programming and extensions. D.C.Heath and company, Lexington.

[21] M.J. Schniederjans and N.K.Kwak (1982). An alternative method for solving goal programming problems; A Reply . The journal of the operational research society ,33,859-860.

[22] D.L.Olson (1984). Comparison of four Goal Programming algorithms. Journals of the operational research society ,35,347-354.

[23] J.P.Ignizio (1982). Linear programming in single and multiple objective system. Prentice Hall. Upper Saddle River ,408-410.

[24] J.L.Arthur and A.Ravindran (1978). An efficient Goal Programming algorithm using constraint partitioning and variable elimination. Management science, 24.867886. 
ELK

Asia Pacific Journals

[25] S.M. Lee, R.L. Morris, (1997). Integer goal programming methods. Tims

Studies in Management Sciences.6, 273-289.
ELK Asia Pacific Journals - Special Issue ISBN: 978-81-930411-4-7

[26] R.E. Markland, S. K. Vickery (1986). The efficient computel

implimentation of a large scale integer goal programming model.

European Journal of Opertional Research. 26, 341-354. 